\title{
CORRECTION
}

\section{Correction to: Inflammatory breast cancer defined: proposed common diagnostic criteria to guide treatment and research}

\author{
R. Jagsi ${ }^{1}$. G. Mason ${ }^{2,3} \cdot$ B. A. Overmoyer ${ }^{4}$-W. A. Woodward ${ }^{5} \cdot$ S. Badve ${ }^{6} \cdot$ R. J. Schneider ${ }^{7}$. J. E. Lang ${ }^{8} \cdot$ M. Alpaugh $^{9}$. \\ K. P. Williams ${ }^{10} \cdot$ D. Vaught ${ }^{11}$ - A. Smith ${ }^{11} \cdot K^{\prime}$. Smith ${ }^{11} \cdot$ K. D. Miller ${ }^{6}$ on behalf of Susan G. Komen-IBCRF IBC \\ Collaborative in partnership with the Milburn Foundation
}

Published online: 8 February 2022

(c) Springer Science+Business Media, LLC, part of Springer Nature 2022

\section{Correction to: Breast Cancer Research and Treatment https://doi.org/10.1007/s10549-021-06434-x}

In the original publication of the article, the Figure 1 was published incorrectly.

The corrected Fig. 1 is given in this correction.

The original article has been corrected.

The original article can be found online at https://doi.org/10.1007/ s10549-021-06434-x.

K. D. Miller

kathmill@iu.edu

University of Michigan, Ann Arbor, MI, USA

2 Inflammatory Breast Cancer Research Foundation, West Lafayette, IN, USA

3 Susan G. Komen Advocates in Science, Dallas, TX, USA

4 Dana Farber Cancer Institute, Boston, MA, USA

5 University of Texas MD Anderson Cancer Center, Houston, TX, USA

6 Indiana University Melvin and Bren Simon Comprehensive Cancer Center, 535 Barnhill Drive, RT 473, Indianapolis, IN 46202, USA

7 New York University School of Medicine, New York, NY, USA

8 Cleveland Clinic, Cleveland, OH, USA

9 Rowan University, Glassboro, NJ, USA

10 North Carolina Central University, Durham, NC, USA

11 Susan G. Komen, Dallas, TX, USA 


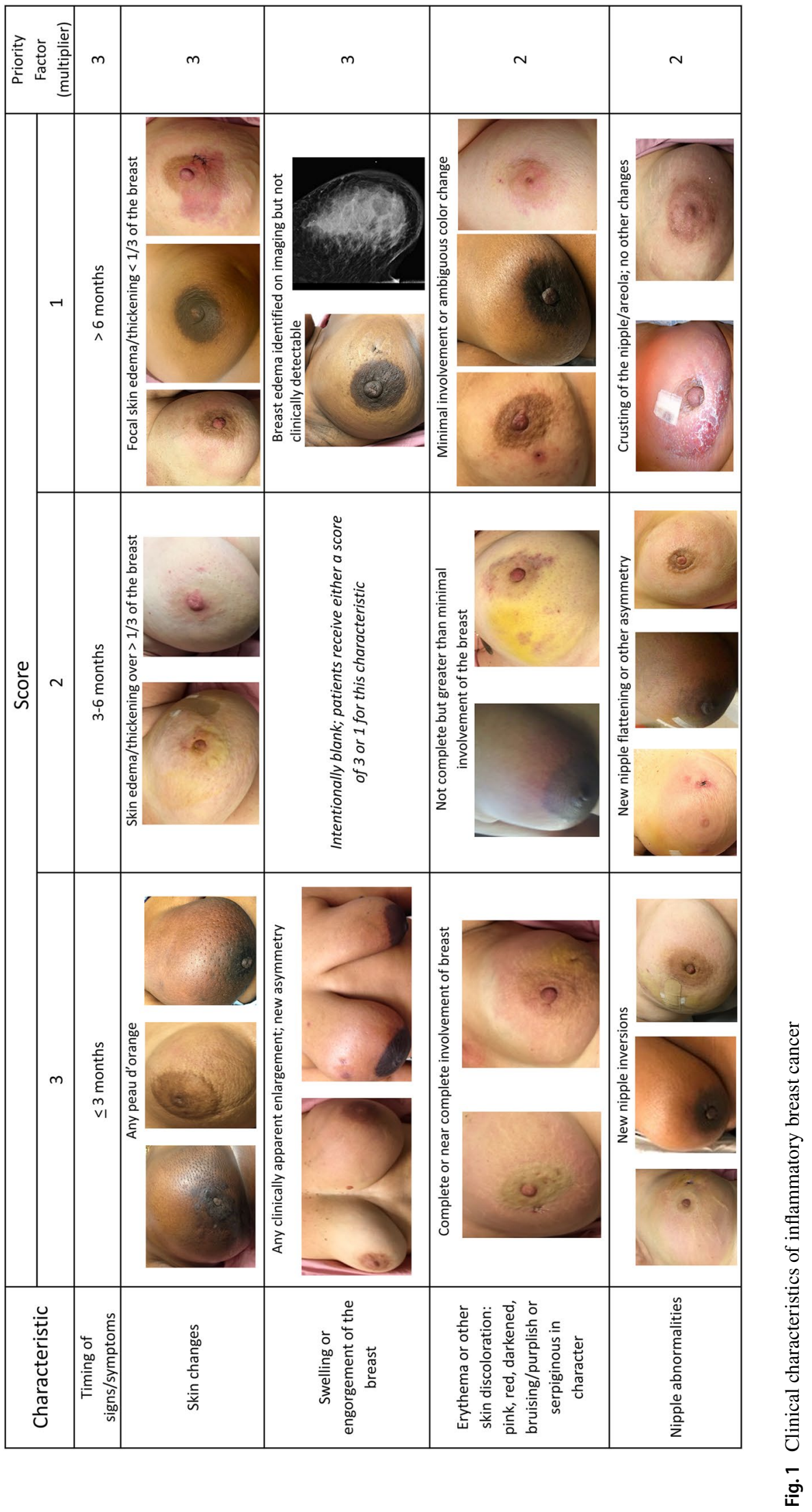


Publisher's Note Springer Nature remains neutral with regard to jurisdictional claims in published maps and institutional affiliations. 